\title{
Emergence of plasmid-mediated multidrug resistance in epidemic and non- epidemic strains of Salmonella enterica serotype Typhi from Jordan
}

\author{
Tarek M. Al-Sanouri ${ }^{1^{*}}$, Bianca Paglietti ${ }^{2 *}$, Aktham Haddadin $^{1}$, Manuela Murgia $^{2}$, \\ Donatella Bacciu ${ }^{2}$, Mohammad Youssef ${ }^{3}$, Salvatore Rubino ${ }^{2}$ \\ ${ }^{1}$ Central Laboratory, Ministry of Health, Amman, Jordan \\ ${ }^{2}$ Department of Biomedical Sciences, University of Sassari, Italy \\ ${ }^{3}$ WHO/Lyon Office for National Epidemic Preparedness and Response (EPR), Lyon, France \\ *Both authors contributed equally.
}

\begin{abstract}
Background: Enteric fever caused by Salmonella enterica serovar Typhi has not been adequately explored in Jordan. Methodology: In this study we investigated antibiotic resistance patterns and resistance determinants coupled with fingerprint methods of forty-eight isolates of $S$. Typhi obtained from 113 patients with suspected enteric fever admitted at six governmental hospitals in different directorates in Jordan. Twenty-four isolates were from an outbreak of typhoid fever that occurred between October 2004 and January 2005, and another twenty-four were from sporadic cases from 2005.

Results: All isolates of $S$. Typhi were resistant to streptomycin. A multidrug resistant (MDR) pattern of ampicillin, chloramphenicol, co-trimoxazole with tetracycline and streptomycin (R-type ACCoTS) was found in 58\% of the epidemic strains causing the outbreak and in $98 \%$ of the strains from sporadic cases. MDR isolates harbored a single IncHI1 plasmid containing a class 1 integron (dfrA7). Plasmid conjugation studies demonstrated a genetic transfer of resistance (ACCoT). S. Typhi isolates were all sensitive to fluoroquinolones and cefotaxime, the alternative drugs recommended for treatment of typhoid fever. The genomic analysis using PFGE showed: a) the outbreak was caused by an introduced circulating clone with/without an MDR plasmid, and b) isolates from the sporadic cases from 2005 are the same MDR clone that persisted and spread in the country. Conclusion: The emergence of MDR S. Typhi strains is a majorn important public health issue in Jordan. This study should guide selection of effective antibiotic therapy for the treatment of typhoid and monitoring of the spread of MDR of S. Typhi.
\end{abstract}

Key Words: Salmonella enterica serovar Typhi, multi-drug resistance plasmid, integrons, Jordan.

J Infect Developing Countries 2008; 2(4): 295-301.

Received 18 March 2008 - Accepted 13 June 2008

Copyright $\odot 2008$ Al-Sanouri et al. This is an open access article distributed under the Creative Commons Attribution License, which permits unrestricted use, distribution, and reproduction in any medium, provided the original work is properly cited.

\section{Introduction}

Typhoid fever caused by Salmonella enterica serotype Typhi (S. Typhi) is currently a significant cause of morbidity and mortality among children and adults in developing countries. In 2004, the World Health Organization (WHO) reported an annual incidence of 22 million cases with more than 216 thousand deaths per year [1]. Transmission of the infection occurs mainly through consumption of contaminated food or water. For this reason, public health measures for the prevention of typhoid fever in developing countries include access to safe chlorinated water, the improvement of food handling practices, and provision of hygiene education to the population.

Chloramphenicol, amoxicillin and trimethoprimsulfamethoxazole represent the first-line drugs for the treatment of uncomplicated typhoid fever, followed by the fluoroquinolones which have been widely introduced for their excellent tissue diffusion [2]. However, multiple resistance to these antibiotics, and more recently to fluoroquinolones, has developed among S. Typhi strains [3-6]. Multidrug resistant (MDR) isolates have been reported as causative agents of numerous outbreaks, dramatically reducing the choice of therapy in many areas of Africa, Southeast Asia and the Indian subcontinent [7-10] where typhoid fever is endemic.

Data, epidemiological studies or reports from the Ministry of Health in Jordan concerning typhoid fever and other enteric diseases in the country are limited. The incidence of infection and outbreaks is not well known and probably underestimated as 
many outbreaks go unnoticed. This is due to the difficulty of monitoring and tracing the spread of pathogens, as there is often a lack of laboratory identification and characterization of the causative agents and no well-organized surveillance system in place.

However, despite improving sanitation levels of drinking water and sewage disposal, Jordan experiences several outbreaks of enteric pathogens every year, implicating contaminated water or food as potential sources of infections. Furthermore, few published reports describing the outbreaks of food-borne and water-borne diseases in the country are available $[11,12]$ and information on antimicrobial resistance determinants and profiles of Salmonella isolates are lacking.

In view of the emergence of MDR strains and their increased involvement in infections and outbreaks worldwide, combining antimicrobial susceptibility testing and molecular fingerprinting of $S$. Typhi has become an important function in public health laboratories (PHLs).

Molecular tools, such as plasmid analysis and Pulsed-Field Gel Electrophoresis (PFGE), extensively used in the laboratories of developed countries for characterizing and subtyping pathogens, are conversely quite limitedly used in laboratories in developing countries, either due to the lack of infrastructure or well-trained microbiologists.

For these reasons, collaboration with institutions from developed countries represents an effective way of improving diagnostic capacity of laboratories and facilitates acquisition of wellestablished molecular typing methods for recognizing and investigating outbreaks of communicable disease in developing countries.

In this context, the WHO Office for Epidemic and Pandemic Alert and Response in Lyon has launched training programmes for strengthening capacity of the national PHLs in developing countries such as Jordan, and to facilitate collaborative research activities and partnership between laboratories from less developed and developed countries.

In the present study we have demonstrated a successful example of a joint research activity involving the University of Sassari in Italy and the Central Laboratory, Ministry of Health, in Jordan, in the investigation of a typhoid outbreak that occurred between October 2004 and January 2005 in the Jordan valley and subsequently in the study of sporadic cases of typhoid fever that occurred in 2005. In this report, Salmonella isolates of serovar Typhi have been studied for susceptibility to antimicrobial agents, molecular determinants of resistance, and their localization on plasmid or integrons. Furthermore, isolates were investigated for their clonal relationship by ribotyping and PFGE techniques.

\section{Materials and Methods \\ Patients}

From October 2004 to January 2006, suspected cases (113 in total) of typhoid fever were admitted at six Government Hospitals (Deir Alla, Al-shoneeh, Ghor-Alsafi, Alsat, Madaba and Al-Karak) located in different directorates in Jordan (Table 1). Patients resided in different rural and periurban areas mostly from Deir Alla in Jordan Valley, about $50 \mathrm{~km}$ west of the capital Amman. Eighty-three cases of typhoid fever were recovered during an outbreak from October 2004 to January 2005. Thirty more sporadic cases were recorded after the outbreak in 2005. All patients exhibited fever $\left(\geq 39^{\circ} \mathrm{C}\right)$, abdominal pain and diarrhoea, and were treated with ceftriaxone intravenous therapy with favourable outcome.

Table 1. Characteristics of Salmonella enterica serovar Typhi strains isolated during an outbreak and from sporadic cases that occurred in Jordan between November 2004 and January 2006.

\begin{tabular}{|c|c|c|c|c|c|}
\hline & .들 & 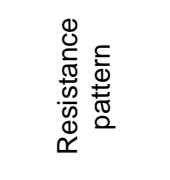 & 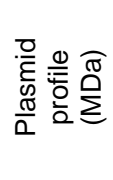 & 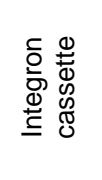 & 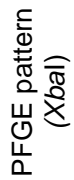 \\
\hline \multirow[t]{4}{*}{$\begin{array}{l}\text { Epidemic } \\
\text { isolates }\end{array}$} & $\begin{array}{l}\text { Deir-Alla } \\
(21)\end{array}$ & $S(10)$ & $\begin{array}{l}\text { plasmid } \\
\text { free }\end{array}$ & Nil & $A$ \\
\hline & & $\begin{array}{l}\text { ACCoTS } \\
\text { (11) }\end{array}$ & 98 & $d f r A 7^{*}$ & A1 \\
\hline & $\begin{array}{c}\text { Al- } \\
\text { shoneeh } \\
\text { (2) }\end{array}$ & ACCoTS (2) & 98 & $d f r A 7$ & A1 \\
\hline & $\begin{array}{l}\text { GhorAl- } \\
\text { Safi(1) }\end{array}$ & ACCoTS (1) & 98 & $d f r A 7$ & A1 \\
\hline \multirow{5}{*}{$\begin{array}{l}\text { Sporadic } \\
\text { isolates }\end{array}$} & Alsalt (8) & ACCoTS (8) & 98 & dfrA7 & A1 \\
\hline & $\begin{array}{l}\text { Alkarak } \\
\text { (1) }\end{array}$ & ACCoTS (1) & 98 & $d f r A 7$ & A1 \\
\hline & $\begin{array}{l}\text { Deir-Alla } \\
\text { (4) }\end{array}$ & ACCoTS (2) & 98 & $d f r A 7$ & A1 \\
\hline & & $S(2)$ & $\begin{array}{l}\text { plasmid } \\
\text { free }\end{array}$ & Nil & $A$ \\
\hline & $\begin{array}{c}\text { Al- } \\
\text { shoneeh } \\
(7)\end{array}$ & ACCoTS (7) & 98 & dfrA7 & A1 \\
\hline
\end{tabular}


Madaba

(4)

A ampicillin, C chloramphenicol, Co cotrimoxazole, T tetracycline, S streptomycin; * the variable region of two isolates was sequenced and indicated the presence of the dfrA7 gene cassette.

Bacterial isolation

Forty-eight cases of typhoid fever, 24 epidemic (29\%) and 24 sporadic (80\%) were bacteriologically confirmed at the Central Laboratory of Ministry of Health in Amman, Jordan. Among the epidemic cases, 20 samples were positive by blood culture and 5 samples by faecal culture (one patient was positive for both faeces and blood; only one isolate was used for further study). All sporadic samples were blood culturepositive. Blood samples were cultured in GCC mono-phase blood culture bottles at $37^{\circ} \mathrm{C}$, examined daily up to 7 days, and subcultured when turbid on blood, MacConkey and Hektoen enteric agar plates (Oxoid, Basingstoke, UK). Stool samples were collected in Cary-Blair transport medium and subsequently plated onto Selenite broth (Oxoid) and cultured on MacConkey and Hektoen enteric agar plates. Definitive identification of the organism was assessed by use of standard biochemical tests followed by serotyping with commercial antisera (Biorad, Segrate, Italy).

\section{Antimicrobial susceptibility testing}

Sensitivity tests of $S$. Typhi isolates were conducted by the standard disc diffusion method and interpreted according to the guidelines provided by the National Committee for Clinical Laboratory Standards (NCCLS, more recently CLSI) [13]. The antibiotic discs (Oxoid) contained ampicillin $(10 \mu \mathrm{g})$, tetracycline $(30 \mu \mathrm{g})$, cotrimoxazole $(25 \mu \mathrm{g})$, chloramphenicol $(30 \mu \mathrm{g})$, streptomycin $(10 \mu \mathrm{g})$, gentamicin $(10 \mu \mathrm{g})$, amoxicillin (20 $\mathrm{gg})$-clavulanic acid $(10 \mu \mathrm{g})$, ciprofloxacin $(5 \mu \mathrm{g})$, nalidixic acid $(10 \mu \mathrm{g})$ and cefotaxime (30 $\mu \mathrm{g})$. Escherichia coli ATCC 25922 was used as a control for the effectiveness of the antibiotic discs.

\section{Plasmid profile analysis and PCR for IncHI1}

Plasmid DNA was extracted from S. Typhi isolates by the alkaline lysis procedure as previously described [14]. Plasmid size was determined by comparing to the standard plasmids of the V517 and 39R861 E. coli reference strains.
To determine the plasmid incompatibility group, PCR amplification was conducted with specific primers for the IncHI1 plasmid as previously described [15].

\section{Integrons detection}

The presence of class 1 and class 2 integrons in genome DNA was detected by PCR with specific primers for integrase gene intl1 [16]. Cassette insertions were detected by sequencing the variable region of the class 1 integron amplified with 5'CS and 3'CS primers and by PCR with specific primers for dhfrA7 $[15,16]$.

\section{Conjugational transfer of drug resistance}

Conjugational transfers were carried out using MDR S. Typhi strains as the donor and E. coli K12 resistant to kanamycin as the recipient. All mating procedures were performed on filters for 18 hours at $37^{\circ} \mathrm{C}$. Transconjugants were screened on LB agar plates containing ampicillin $(100 \mu \mathrm{g} / \mathrm{ml})$, kanamycin $(50 \mu \mathrm{g} / \mathrm{ml})$ or tetracycline $(10 \mu \mathrm{g} / \mathrm{ml})$. $E$. coli transconjugants were confirmed by lactose fermentation and/or failure to agglutinate Omni-O and Vi antisera, and then tested for antibiotic susceptibility and analysed for the presence of both the plasmid and the intl1 gene.

\section{Ribotyping}

Genomic DNA was extracted according to Ausubel et al. [17]. Pvull digested DNA was transferred to a nylon membrane (Hybond $\mathrm{N}+$, Amersham) using an VacuGeneTM XL vacuum system (Pharmacia Biotech) and hybridized with a PCR-generated non-radioactive labelled probe for 16S RNA under stringent conditions as described by Stanley et al. [18].

\section{PFGE genotyping}

A representative set of epidemic and sporadic strains of $S$. Typhi were typed by PFGE according to a European standardised protocol described by Peters et al. in the Salm-gene project [19]. Genomic DNA plugs were digested with 20 units of $X$ bal or Spel (Promega) and subjected to electrophoresis (Pharmacia system) at $14^{\circ} \mathrm{C}$ for 22 hours at $180 \mathrm{~V}$, interpolating, with a pulse time of 2s-64s. Analysis of macrorestriction patterns was carried out according to Tenover et al. [20].

\section{Results}




\section{The outbreak}

The weekly curve of the outbreak (Figure 1) shows a constant increase of cases per week until 17 December 2004, when the incidence of cases started to decline. The age group of patients was distributed between 2 and 38 years, with a predominance in children 5 to 14 years old, as shown in Figure 2.

Figure 1. Epidemic curve of the outbreak by week number (October 2004-January 2005).

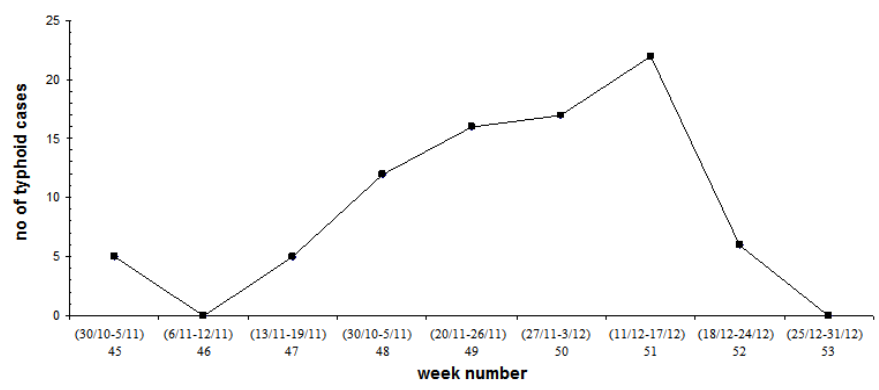

Figure 2. Distribution of typhoid cases by age.

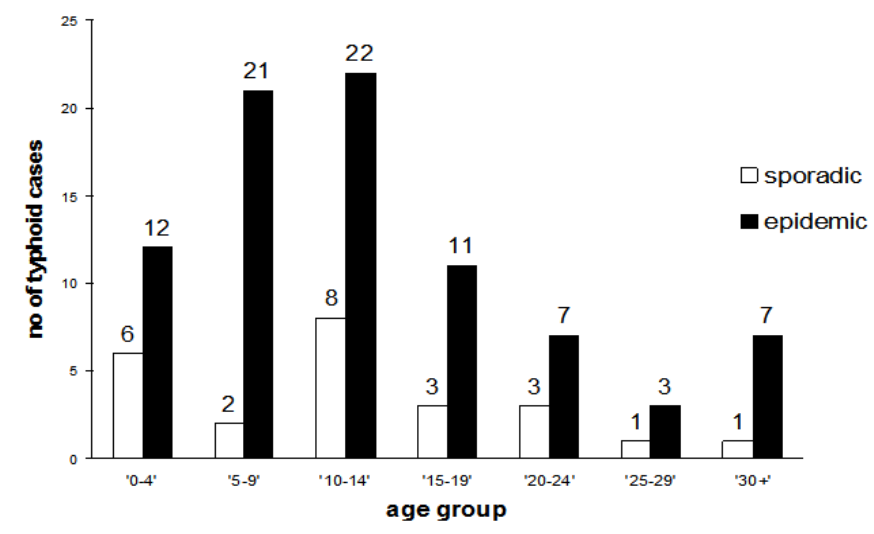

Bacterial isolates and antimicrobial sensitivity testing

A total of forty-eight S. Typhi strains, 24 from the outbreak and 24 sporadic, were isolated from bloodstream or stool samples. The table provides the details of antibiotic resistance patterns, plasmid profiles, integrons, and PFGE patterns among the isolates. There was no consistent change in antimicrobial resistance patterns. All S. Typhi isolates were resistant to streptomycin, $75 \%$ of which showed additional multidrug resistance to ampicillin, chloramphenicol, co-trimoxazole and tetracycline (R-type ACCOTS), which represents the first-line of drugs for treating typhoid fever in Jordan. The MDR strains persisted after the outbreak (October 2004-January 2005), whereas streptomycin mono-resistant strains seem to disappear (Figure 3). None of the isolates collected from 2004 to 2006 were resistant to nalidixic acid, ciprofloxacin, amoxicillin, gentamicin or cefotaxime.

Figure 3. Trends of Multiple drug resistant (MDR) Salmonella enterica serovar Typhi strains from epidemic and non-epidemic cases of typhoid fever from Jordan (November 2004-January 2006). A, ampicillin; C, chloramphenicol; $\mathrm{Co}$, Co-trimoxaxole.

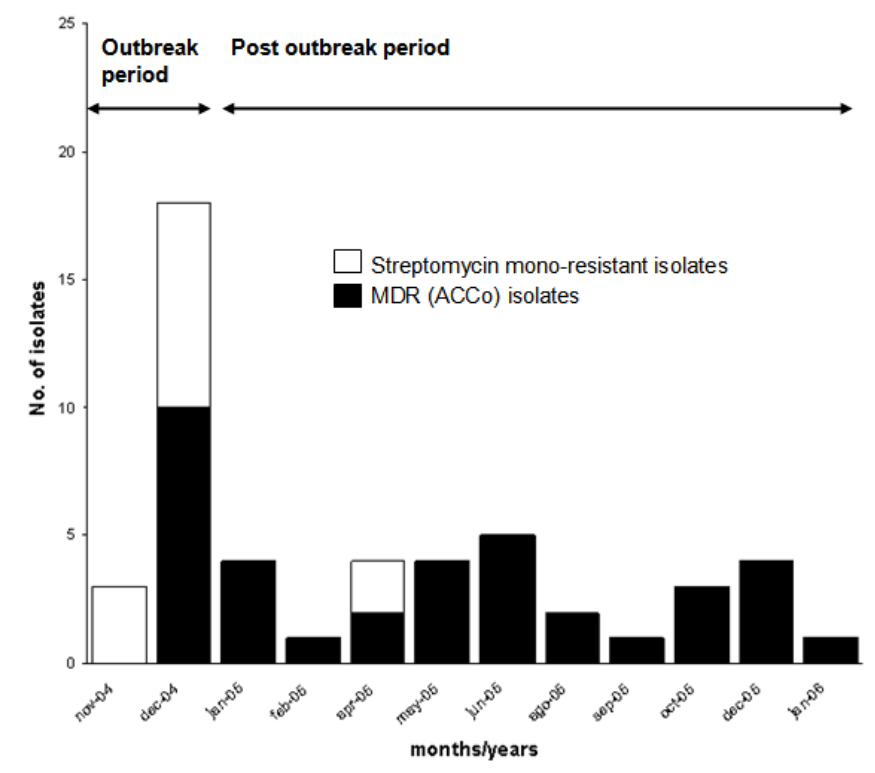

Figure 4. Pulsed-field gel electrophoresis (PFGE) patterns of $S$. Typhi isolates from Jordan. A. Xbal patterns B. Spel patterns. M 0.1-200 kb molecular weight marker (Sigma). Lanes 1-3, 9: streptomycin resistant isolates; lanes 4-8: MDR isolates.

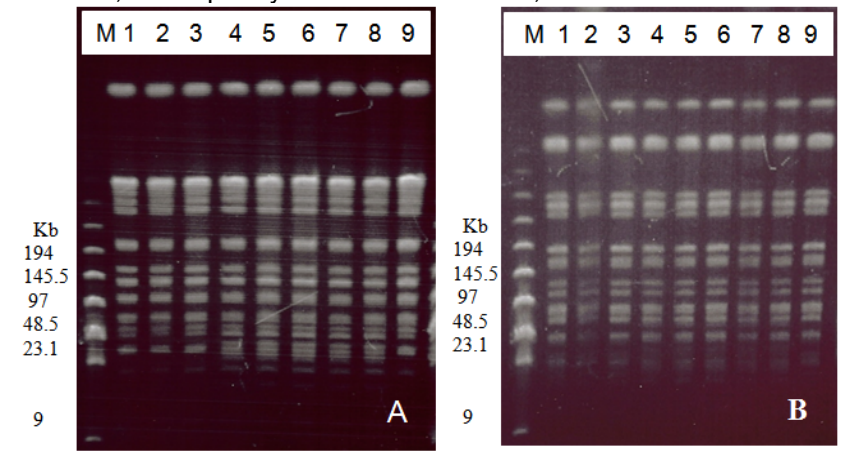

Antibiotic resistance determinants

We investigated the possible relationship between antibiotic resistance and genetic determinants (plasmids and integrons). Since MDR in S. Typhi is mainly due to large conjugative plasmids, strains were subjected to alkali lysis to isolate high molecular weight plasmids. A plasmid of incompatibility group IncHI1 of about $98 \mathrm{MDa}$ 
was found in all MDR Typhi isolates (R-type ACCoTS); on the contrary, streptomycin resistant isolates were plasmid-free (Table 1). R-type ACCoTS Typhi also harbored a class 1 integron of 800bp. Class 2 integrons were not detected. Sequencing of class 1 integron variable regions revealed the presence of a single gene cassette dhfrA7 which confers resistance to trimethoprim. A representative number of MDR Typhi isolates were tested for the transferability of their resistances to E. coli $\mathrm{Km}^{\mathrm{R}}$ by conjugation experiments. Interestingly, resistance to ACCOT, but not streptomycin, was co-transferred with the Rplasmid and the dhfrA7-integron, which was found to be plasmid-borne as demonstrated by intl1 gene $\mathrm{PCR}$-detection of $E$. coli tranconjugants.

\section{Molecular fingerprint methods}

In order to study the clonal relationship among $S$. Typhi isolates responsible for the outbreak and the relationship between these isolates and those from sporadic cases isolated after the outbreak, molecular typing was performed by ribotyping and PFGE methods on 30 randomly selected strains (Table). A remarkable homogeneity of PFGE patterns with two to three fragments difference in the range 48.5-23.1 $\mathrm{kb}$ was identified after analysis of DNA restricted with Xbal or Spel endonucleases (Figure 4). Thus, only the results of Xbal digestion were used for analysis. In particular, plasmid-free isolates lacked the fragments present in MDR strains after restriction, relating these fragments to plasmid carriage. This association was also confirmed by hybridization experiments with a specific probe for the integrase 1 gene (data not shown). When plasmid-associated bands were removed from the analysis, all isolates had an identical PFGE pattern. Results also showed complete correlation between resistance typing and PFGE. The PFGE patterns of $S$. Typhi isolates were compared with the patterns obtained previously with an rRNA gene probe. Ribotyping identified the clonality by showing a unique pattern (data not shown), while the PFGE approach was able to discriminate between MDR-plasmidbearing and plasmid-free isolates.

\section{Discussion}

Typhoid fever is becoming a serious problem in several countries of the Middle East such as Oman, Qatar, Kuwait, Saudi Arabia, Turkey and
Iran [21-25], possibly due to the introduction of MDR isolates of $S$. Typhi by expatriates from the Indian sub-continent employed in these countries, as well as from nationals visiting the Indian subcontinent. Although typhoid caused by MDR serovar Typhi in most endemic parts of Asia and the Indian subcontinent $[26,27]$ have been well characterized, to date data on antimicrobial resistance among $S$. Typhi from Jordan are limited.

This is the first report of $S$. Typhi from Jordan since 1980 , which arguably is tightly linked to the movement of migrant workers continuously employed in the national agricultural field, particularly in the Jordan Valley region, the area under study in the present investigation. We report in this study the characterization of 48 clinical isolates of $S$. Typhi geographically distributed in Jordan by combining phenotypic and molecular typing methods. The data presented highlight the emergence of a high rate of $S$. Typhi showing multiple resistance to the common antimicrobial agents used in the treatment of typhoid fever in developing countries. The prevalence of MDR resistant to ampicillin, chloramphenicol, cotrimoxazole, streptomycin and tetracycline was high in epidemic isolates (58\%), but was more pronounced $(92 \%)$ in isolates from sporadic cases that occurred in different locations during 2005, suggesting a spread of this MDR clone through the country. This finding contradicts recent reports from some regions where the incidence of MDR Typhi isolates appears to have decreased $[28,29]$.

The high frequency of MDR S. Typhi isolated is remarkable, since resistance to first-line drugs will require more expensive drugs for effective treatment of typhoid fever and may pose a major challenge to the health care system.

However, the susceptibility exhibited to fluoroquinolone drugs (nalidixic acid and ciprofloxacin) and cefotaxime leaves valuable therapeutic options in the treatment of MDR typhoid fever. This again contradicts what was recently reported from different studies that showed an increased incidence of high resistance to fluoroquinolone which was also associated with treatment failures [30].

Interestingly, the emergence of MDR in $S$. Typhi isolates from Jordan is linked to an IncHI1 [15] conjugative plasmid which mediates multiple resistance, demonstrated by conjugation 
experiments. It has been reported that similar plasmids have been isolated in S. Typhi strains from different countries in the Middle East and Asia that are able to transfer full MDR or partial resistance [31], which is similar to our findings. The presence of strains harboring the IncHI1 plasmid after the outbreak is of concern and poses the problem of it continuing to spread [32] and transfer resistance.

Besides plasmids, mobile elements contribute to the dissemination of antibiotic resistance and integrons represent the major vehicle for spread [33]. In this study, all MDR S. Typhi strains harbored a class 1 integron carrying the dfrA7 gene cassette, conferring resistance to trimethoprim, which is similar to the results of earlier studies on other $S$. Typhi isolates from different countries of South East Asia [8,15]. The presence of the integron must not be undervalued since two reports have already described multidrug-resistant $S$. Typhi strains harboring integrons with up to six drug resistance genes $[34,35]$. Furthermore, integrons can acquire additional resistance gene cassettes such as veb1 or blaVIM, leading to serious problems in the management of these infections.

PFGE of macrorestricted DNA produced two major patterns when Xbal and Spel were used. S. Typhi strains circulating in Jordan and responsible for the outbreak were most probably derived from an introduced clone possessing a plasmid or not, based on the analysis of resistance patterns and PFGE. Our results indicate that these MDR $S$. Typhi strains are spreading from the outbreakaffected areas to other regions. This situation is of concern and should be carefully monitored in Jordan.

The PFGE pattern of MDR S. Typhi strains investigated was apparently identical to one of the five $X$ bal-PFGE-patterns identified as circulating MDR S. Typhi strains in Asia and Middle Eastern countries in previous studies $[8,26,27,36]$. These findings confirm that MDR strains from Jordan are related to those in other countries and could have been introduced possibly about November 2004 or even before. Unfortunately, no samples of $S$. Typhi strains are available from previous years to investigate that retrospectively.

Phenotypic and genotypic typing methods have been demonstrated to be useful to investigate outbreaks and track the spread of MDR of S. Typhi in Jordan. Thus, for the implementation of national prevention measures, it is important to identify the source of an outbreak and to understand the mode of transmission of MDR S. Typhi. Further studies based on molecular typing methods are also needed in Jordan to characterize $S$. Typhi isolates associated with sporadic cases in order to compare their genotypic profile to those characterized in the current study. Such an effort would will provide background information on the distribution of MDR S. Typhi strains and enable the national health authorities to forecast potential sources of outbreak infections.

In conclusion, this study describes the molecular characterization of clinical isolates of $S$. Typhi for the first time in Jordan, and the importance of the use of molecular typing techniques from a public health perspective.

\section{Acknowledgments}

This work has been partially supported by funds from the Sardinia Regional Government, Italy. We are grateful to Duy Phan from the Wellcome Trust Sanger Institute for providing primers and IncHII positive control.

\section{References}

1. Crump JA, Lubsy SP, Mintz ED (2004) The global burden of enteric fever. Bull World Health Organ 82:346-53.

2. WHO Background document (2003) The diagnosis, treatment and prevention of typhoid fever. WHO/V\&B/03.07. 37.

3. Rowe B, Ward LR, Threlfall EJ (1997) Multidrug-resistant Salmonella typhi: a worldwide epidemic. Clin Infect Dis 24:106-109.

4. Murdoch DA, Banatvaia NA, Bone A (1998) Epidemic ciprofloxacin resistant Salmonella typhi in Tajikistan. Lancet 351:339.

5. Wain J, Hoa NT, Chinh NT (1997) Quinolone-resistant Salmonella Typhi in Vietnam: molecular basis of resistance and clinical response to treatment. Clin Infect Dis 25:1404-1410.

6. Gaind R, Paglietti B, Murgia M, Dawar R, Uzzau S, Cappuccinelli P, Deb M, Aggarwal P, Rubino S (2006) Molecular characterization of ciprofloxacin-resistant Salmonella enterica serovar Typhi and Paratyphi A causing enteric fever in India. J Antimicr Chemother 58(6):1139-44.

7. Kariuki S, Gilks C, Revathi G, Hart CA (2000) Genotypic analysis of multidrug-resistant Salmonella enterica serovar Typhi, Kenya. Emerg Infect Dis 6:649-651.

8. Lee K, Yong D, Yum JH, Lim JS, Kim HS, Lee BK, Chong $Y$ (2004) Emergence of multidrug resistant Salmonella enterica serovar Typhi in Korea. Antimicrob Agents Chemother 48:4130-4135,

9. Mirza S, Beeching NJ, Hart CA (1996) Multidrug resistant typhoid: a global problem. J Med Microbiol 44:317-9.

10. Threlfall EJ, Ward LR, Rowe B, Raghupathi S, Chandrasekaran V, Vandepitte J, Lemmens P (1992) 
Widespread occurrence of multiple drug-resistant Salmonella Typhi in India. Eur J Clin Microbiol Infect Dis 11:990-993.

11. Khuri-Bulos NA, Abu Khalaf $M$, Shehabi A, Shami K (1994) Foodhandler-associated Salmonella outbreak in a university hospital despite routine surveillance cultures of kitchen employees. Infect Control Hosp Epidemiol 15(5):311-314.

12. Shehabi AA (1995) Extra-Intestinal infections with multiply drug-resistant Salmonella typhimurium in hospitalized patients in Jordan. Eur J Clin Microbiol Infect Dis 14:448-451.

13. National Committee for Clinical Laboratory Standards. 2000. Methods for dilution antimicrobial susceptibility tests for bacteria that grow aerobically. Approved standard M7-A5. National Committee for Clinical Laboratory Standards, Wayne, Pa.

14. Kado Cl and Liu ST. 1981. Rapid procedure for detection and isolation of large and small plasmids. J Bacteriol 145:1365-73.

15. Wain J, Diem Nga LT, Kidgell C, James K, Fortune S, Diep TS, Ali T, O’ Gaora P, Parry C, Parkhill J, Farrar J, White NJ, Dougan G (2003) Molecular Analysis of incHI1 Antimicrobial Resistance Plasmids from Salmonella Serovar Typhi Strains Associated with Typhoid Fever. Antimicrob Agents Chemother 2732-2739.

16. Ploy MC, Denis F, Courvalin P, Lambert T (2000) Molecular characterisation of integrons in Acinetobacter baumannii: description of a hybrid class 2 integron. Antimicrob Agents Chemother 44:2684-2688.

17. Ausubel FM, Brent R, Kingston RE (1996) Current Protocols in Molecular Biology. John Wiley \& Sons, New York.

18. Stanley J, Baquar N, Threlfall EJ (1993) Genotypes and phylogenetic relationships of Salmonella typhimurium are defined by molecular fingerprinting of IS200 and 16S rrn loci. J Gen Microbiol 139:1133-40.

19. Peters TM, Maguire C, Threlfall EJ, Fisher IST, Gill N, Gatto AJ on behalf of the Salm-gene project participants (2003) The Salm-gene project - a European collaboration for DNA fingerprinting for food-related salmonellosis. Euro Surveill 8(2):46-50.

20. Tenover FC, Arbeit RD, Goering RV, Mickelsen PA, Murray BA, Persing DH, Swaminathan B (1995) Interpreting chromosomal DNA restriction patterns produced by pulsed-field gel electrophoresis: criteria for bacterial strain typing. J Clin Microbiol 33:2233-2239.

21. Elshafie SS, Rafay AM (1992) Chloramphenicol-resistant tyhoid fever: an emerging problem in Oman. Scand J Infect Dis 24(6):819-820.

22. Uwaydah AK, Matar I, Chacko KC, Davidson JC (1991) The emergence of antimicrobial resistant Salmonella Typhi in Qatar: epidemiology and therapeutic implications. Trans R Soc Trop Med Hyg 85(6):790-792.

23. Panigrahi D, Al-Aneziz AH, West PWJ (1996) Plasmidmediated multidrug resistance in Salmonella Typhi in Kuwait. Trop. Med \& International Health 1(4):439-442.

24. Hosoglu S, Loeb M, Gejik MF, Ucmak H, Jayaratne $P$ (2003) Molecular epidemiology of invasive Salmonella Typhi from southeast Turkey. CDI 9:727-30.
25. Bahrmand AR and Velayati AA (1997) Antimicrobial resistance pattern and plasmid profile of Salmonella Typhi isolated from an outbreak in Tehran. Scand J Infect Dis 29 (3):265-269.

26. Shanahan PM, Karamat KA, Thomson CJ, Amyes SG (1998) Molecular analysis of and identification of antibiotic resistance genes in clinical isolates of Salmonella Typhi from India. J Clin Microbiol 36:15951600.

27. Hampton MD, Ward LR, Rowe B, Threlfall EJ (1998) Molecular fingerprinting of multidrug-resistant Salmonella enterica serotype Typhi. Emerg Infect Dis 4:317-20.

28. Rodrigues C, Shennai S, Mehta A (2003) Enteric fever in Mumbai, India: the good news and the bad news. Clin Infect Dis 36:535.

29. Wasfy MO, Frenck R, Ismail TF, et al.: Trends of multipledrug resistance among Salmonella serotype Typhi isolates during a 14-year period in Egypt. Clin Infect Dis 2002, 35:1265-1268.

30. Asna SM, Haq JA, Rahman MM (2003) Nalidixic acidresistant Salmonella enterica serovar Typhi with decreased susceptibility to ciprofloxacin caused treatment failure: a report from Bangladesh. Jpn J Infect Dis 56:3233.

31. Mirza S, Kariuki S, Mamum KZ, Beeching NJ, Hart CA (2000) Analysis of plasmid and chromosomal DNA of multidrug-resistant Salmonella enterica serovar Typhi from Asia. J Clin Microbiol 38:1449-1452.

32. Doyle $M$, Fookes $M$, Ivens A, Mangan MW, Wain J, Dorman CJ (2007) An H-NS-like Stealth Protein Aids Horizontal DNA Transmission in Bacteria. Science 315(5809):251-252.

33. Liebert CA, Hall RM, Summers AO (1999) Transposon Tn21, flagship of floating genome. Microbiol Mol Biol Rev 63:507-522

34. Ploy MC, Chainier D, Thi NHT, Poilane I, Cruaud P, Denis F. et al (2003) Integron-associated antibiotic resistance in Salmonella enterica serovar Typhi from Asia. Antimicrob Agents Chemother 47:1427-1429.

35. Pai H, Byeon JH, Yu S, Lee BK, Kim S (2003) Salmonella enterica serovar Typhi strains isolated in Korea containing a multiresistance Class 1 integron. Antimicrob Agents Chemother 47:2006-2008.

36. Kubota K, Barret TJ, Ackers ML, Brachman PS, Mintz ED (2005) Analysis of Salmonella enterica serotype Typhi Pulsed-Field Gel Electrophoresis patterns associated with international travel. J Clin Microbiol 43(3):1205-1209.

Corresponding Author: Bianca Paglietti, Address: Department of Biomedical Sciences, University of Sassari, V.le San Pietro 43/b 07100 Sassari, Italy, Telephone:+39 079-228302, Fax: 39 079-212345, Email: biancap@uniss.it

Conflict of interest: No conflict of interest is declared. 